\title{
Flourishing: Role of Perseverance and Passion for Long-Term Goals in Relation to Subjective Vitality
}

\author{
Meera Padhy ${ }^{1}$, Meena Hariharan², Suma Lavanya Mutnury ${ }^{3}$, \\ Oindrila Mukherjee ${ }^{3}$
}

\author{
${ }^{1}$ Assistant Professor, Centre for Health Psychology, University of Hyderabad, Telangana - 500046 \\ ${ }^{2}$ Professor, Centre for Health Psychology, University of Hyderabad, Telangana - 500046 \\ ${ }^{3}$ Research Scholar, Centre for Health Psychology, University of Hyderabad, Telangana - 500046
}

Corresponding Author: Meera Padhy

\begin{abstract}
Several psychosocial factors contribute to flourishing which is a state of optimal human functioning. The objectives of this study were to explore the relationship between grit, vitality and flourishing; and to assess the impact of grit and vitality on flourishing. A correlational design was used to collect data from 449 participants ( 211 women and 238 men) aged between 18-57 years. The Flourishing Scale, the Grit Scale and the Subjective Vitality Scale were administered. The obtained data were scored and analyzed suitably. Results revealed positive relationships between all the variables. Further, hierarchical multiple regression analyses showed that grit and vitality significantly predicted flourishing. Results from this study indicate the need to further investigate the impact of grit and vitality on an important positive psychological construct like flourishing.
\end{abstract}

Keywords: flourishing, grit, vitality, regression, correlation, well-being

\section{INTRODUCTION}

Flourishing is a key indicator of well-being. It is a state of optimal human functioning as opposed to languishing and mental illness (Baumgardner \& Crothers, 2015). ${ }^{[1]}$ Flourishing is associated with several aspects of mental as well as physical health. Fostering human flourishing is important to improve the quality of life of people. Therefore, the need arises for research to look into the correlates of flourishing. Not much research has been carried out to understand the relationship between important positive psychological variables like grit and vitality with flourishing. This calls for exploring flourishing by researchers cross-culturally.

Research previously focused on the importance of cognitive traits as indicators of success, specifically in the case of academic success. It was only recently that Duckworth et al. (2007) ${ }^{[2]}$ contributed to the paradigm shift in research related to non-cognitive traits such as grit, concluding the effect of these traits on an individual's life and character. The non-cognitive traits are essentially understood as those variables associated with an individual's motivation, attitude and temperament among others rather than intellect (Stoffel \& Cain, 2018). ${ }^{[3]}$

The American Psychological Association (2020) ${ }^{[4]}$ defined grit as "a personality trait characterized by perseverance and passion for achieving long-term goals and grit entails working strenuously to overcome challenges and maintaining effort and interest over time despite failures, adversities, and plateaus in progress." Though grit and resilience have been used interchangeably across literature, they are completely different constructs. Masten (2014) ${ }^{[5]}$ defined resilience as the capacity of a dynamic system to adapt 

vitality.

successfully to disturbances that threaten the viability, the function, or the development of that system; grit is explained as passion and perseverance towards long-term goals and having the stamina to stick with one's future to persist and pursue hard to turn that future into a reality for oneself (Duckworth et al., 2007). ${ }^{[2]}$

Grit is also associated with other variables such as consistency of interest, perseverance of effort and ambition.

Consistency of interests refers to an individual's inclination towards cultivating and maintaining a specific range of interests regularly, over a long period of time. In other words, it refers to the uniformity in nurturing all of an individual's interest areas. Although strongly associated with grit in western studies, consistency of interests was not found to be relevant to collectivistic cultural groups. People in collectivist societies have demonstrated a lower need for consistency of interests (Datu et al., 2016). ${ }^{[6]}$

In line with grit, the construct of perseverance of effort refers to the persistence and determination of an individual towards a goal. It indicates the hard work and sustained effort an individual shoulders, in spite of challenges, to achieve the desired goal. Gritty individuals are generally found to experience high levels of perseverance of effort (Datu et al., 2016). ${ }^{[7]}$

Ambition is one of those variables closely associated with grit in the field of psychology (NKP \& Shobanah, 2017). ${ }^{[8]}$ While grit is defined as a stable trait not requiring any immediate positive feedback to sustain a goal (Duckworth et al., 2007), ${ }^{[2]}$ ambition is understood as an intrinsic desire to gain recognition, power or success for one's achievements (Maltby et al., 2008). ${ }^{\text {[9] }}$

Vitality has been associated with better psychological and cognitive functioning. Subjective vitality is defined as a feeling of liveliness and a sensation of personal energy (Ryan \& Fredrick, 1997). ${ }^{[10]}$ Ryan and Deci (2001) [11] considered vitality to be an aspect of eudaimonic well-being. It essentially refers to the state of organismic well-being, feeling alive and alert, as being vital and energetic contributes to a fully functioning and psychologically sound individual. Ancient Eastern practices like tai chi, yoga, and meditation are also known to result in the experience of vitality. And vitality is seen to enhance problem-solving, concentration, performance, and greater readiness for new challenges. Vitality is distinct from happiness and subjective wellbeing in that it constitutes higher levels of experienced activation or energy as well as positive affect (Lopez, Pedrotti \& Snyder, 2018). ${ }^{[12]}$

The growing interest in positive psychology has led to increased research in the area of flourishing. Conceptualized by Keyes (2002) ${ }^{[13]}$ and further developed by Fredrickson and Losada (2005), ${ }^{[14]}$ flourishing can be defined as living "within an optimal range of human functioning" (Fredrickson \& Losada, 2005). ${ }^{[14]}$ It is a descriptor of well-being and positive mental health. Flourishing individuals experience a high level of positive emotions, psychological functioning and social functioning (Keyes, 2002). ${ }^{[13]}$ It is the opposite of mental illness and has been contrasted with languishing over a long period of time (Baumgardner \& Crothers, 2015). ${ }^{[1]}$

Languishing is a state described by people as being 'hollow', 'empty' or 'stagnant'. The languishing state creates a division in the illness-wellness continuum with respect to an individual's psychological health. The languishing state is characterized by few symptoms of mental illness and few symptoms of mental health (wellness) as well. Therefore, languishing individuals have few symptoms of pathology but not enough to be diagnosed as being mentally ill. Flourishing, in other words, is a state of complete mental health. Flourishing individuals experience both positive and negative emotions but have more adaptive coping strategies than those who are languishing (Keyes, 2002; 

vitality.

Fredrickson \& Losada, 2005; Baumgardner \& Crothers, 2015). ${ }^{[13,14,1]}$

Grit has been related to academic success (Hodge et al., 2018) ${ }^{[15]}$; happiness (Singh \& Jha, 2008) ${ }^{[16]}$; satisfaction and a sense of belongingness (Bowman et al., 2015) ${ }^{[17]}$; psychological well-being (Goodman et al., 2017) ${ }^{[18]}$; value and selfefficacy (Muenks et al., 2017, 2018) ${ }^{[19-20]}$; and self-esteem (Weisskirch, 2018) ${ }^{[21]}$ etc. It is important to understand the relationship between grit and psychological variables such as self-control, resilience and perceived stress amongst others (Kannagara et., 2018). ${ }^{[22]}$

The construct of subjective vitality refers to the feeling of being alert, alive and full of energy (Ryan \& Fredrick, 1997) ${ }^{[10]}$. Although it has been studied in relation to different constructs, very limited research has examined the link between subjective vitality and flourishing. However, as subjective vitality is an aspect of well-being (Ryan \& Deci, 2001; McMahan \& Estes, 2011) ${ }^{[11,23]}$ and flourishing is a measure of psychological well-being, it may be said that vitality and flourishing are connected to each other. The relationship between grit, vitality and flourishing has not been explored extensively yet and this study attempts to examine the same.

The current study aimed at assessing the impact of grit and vitality on flourishing.

\section{MATERIALS AND METHODS}

A correlational design was used in the study.

\section{Participants}

Purposive sampling technique was adopted to recruit participants for the study. The sample consisted of 449 participants (211 women and 238 men) across various socioeconomic groups, occupations and levels of education. The age range of the participants was $18-57$ years $(M=24.39, S D$ = 8.99).

\section{Tools}

Three psychological tools have been used to collect data along with the demographic data sheet and informed consent form of the participants. Demographic details such as age, gender, education level, occupation, marital status, and the duration of illness were collected from each participant. A brief description of the tools used in the study is given below:

The Flourishing Scale developed by Diener et al. (2010) ${ }^{[24]}$ consists of eight items describing important aspects of human functioning viz. positive relationships, feelings of competence, having meaning and purpose in life. The response of each item is on a 7-point Likert scale ranging from 1 (Strongly Disagree) to 7 (Strongly Agree). This measure has a high internal consistency with Cronbach's alpha of 0.87 . Cronbach's alpha for this study was 0.89 .

Grit Scale developed by Duckworth et al. (2007) ${ }^{[2]}$ consists of 17 items that measure the perseverance and passion for long-term goals. The response of each item is on a 5-point Likert scale ranging from 1 (Not like me at all) to 5 (Very much like me). In addition to grit, the scale consists of consistency of interest subscale, the perseverance of effort subscale and ambition subscale. This measure has a high internal consistency with Cronbach's alpha of 0.85 . Cronbach's alpha for this study was 0.69 .

The Subjective Vitality Scale was validated at both levels by Ryan and Frederick (1997). ${ }^{[10]}$ This was the original scale consisting of 7 items. Bostic, Rubio, and Hood (2000) ${ }^{[25]}$ using confirmatory factor analysis deduced a 6-item version of the scale form the original measure. This scale has a high internal consistency with Cronbach's alpha of 0.96 (Fini et al, 2010). ${ }^{[26]}$ Cronbach's alpha for this study was 0.73 .

\section{Procedure}

The participants were approached and the purpose of the study was explained to them. The participants were assured of the confidentiality of their personal details and responses. Informed consent was obtained from those participants willing to 

vitality.

be a part of the study. Subsequently, the demographic details were collected and the participants were given the questionnaires.

\section{Statistical Analysis}

The quantitative data were analyzed using SPSS 23. The statistics used to analyze the data were descriptive statistics. Pearson's Product Moment Correlation (r) and multiple hierarchical regression were performed. In the analysis, the predictors were grit, consistency of interest, ambition, perseverance of effort and vitality. The criterion was flourishing. Prior to hierarchical regression analysis, Pearson's $r$ was computed to find a linear relationship between the predictors and criterion; and to identify the suitable predictors to be entered into the model.

\section{RESULT}

Table 1. The values of Pearson's r along with descriptive statistics (M and $\boldsymbol{S D})(\mathbf{N}=\mathbf{4 4 9})$
\begin{tabular}{|l|l|l|l|l|l|l|l|l|}
\hline & $\mathbf{M}$ & $\mathbf{S D}$ & $\mathbf{1}$ & $\mathbf{2}$ & $\mathbf{3}$ & $\mathbf{4}$ & $\mathbf{5}$ & $\mathbf{6}$ \\
\hline 1.Grit & 37.68 & 6.63 & 1 & $.75^{* *}$ & $.38^{* *}$ & $.73^{* *}$ & $.36^{* *}$ & $.30^{* *}$ \\
\hline 2.Consistency of Interest & 17.96 & 4.55 & & 1 & .07 & $.10^{*}$ & .08 & .06 \\
\hline 3.Ambition & 17.20 & 3.35 & & & 1 & $.51^{* *}$ & $.44^{* *}$ & $.45^{* *}$ \\
\hline 4.Perseverance of Effort & 19.73 & 4.39 & & & & 1 & $.46^{* *}$ & $.39^{* *}$ \\
\hline 5.Vitality & 28.81 & 7.25 & & & & & 1 & $.53^{* *}$ \\
\hline 6.Flourishing & 41.17 & 9.49 & & & & & & 1 \\
\hline
\end{tabular}

Hierarchical multiple regression was performed to investigate the ability of grit, ambition, and perseverance of effort to predict levels of flourishing, after controlling for vitality. Preliminary analyses were conducted to ensure no violation of the assumptions of normality, linearity, and homoscedasticity. Additionally, the correlations amongst the predictor variables included in the study were examined and these are presented in Table 1. All correlations between predictor variables and the criterion variable were moderate, ranging between $\mathrm{r}=.30, \mathrm{p}<.01$ and $\mathrm{r}=.53$, $\mathrm{p}<.01$. This indicates that multicollinearity was unlikely to be a problem. All predictor variables were statistically correlated with flourishing which indicates that the data were suitably correlated with the dependent variable for examination through multiple hierarchical regression to be reliably undertaken. Only one predictor variableconsistency of interest subscale was not correlated with flourishing. Hence it was not included in the model.

Table 2: Hierarchical Regression Analysis for Grit and its dimensions and subjective vitality predicting flourishing

\begin{tabular}{|l|c|c|c|c|c|c|c|}
\hline Model & $\mathbf{B}$ & $\mathbf{S E}$ & $\boldsymbol{\beta}$ & Adjusted $\quad \mathbf{R}^{\mathbf{2}}$ & $\mathbf{R}^{\mathbf{2}}$ & $\Delta \mathbf{R}^{\mathbf{2}}$ \\
\hline Model 1 (C=14.64, F=46.91***) & & & & & .24 & .24 & \\
\hline Grit & .04 & .09 & & .03 & & & \\
\hline Ambition & .97 & .14 & & $.34 * * *$ & & & \\
\hline Perseverance & .43 & .14 & & $.20^{* *}$ & & & \\
\hline Model 2 (C=11.05, F=58.06**) & & & & & .34 & .34 & .10 \\
\hline Grit & .01 & .08 & & .00 & & & \\
\hline Ambition & .68 & .13 & $.24 * * *$ & & & \\
\hline Perseverance & .20 & .13 & & .09 & & & \\
\hline Vitality & .49 & .06 & & $.38^{* * *}$ & & & \\
\hline
\end{tabular}

Table 2 shows the summary of hierarchical regression. In the first step of hierarchical multiple regression the predictor variables grit, ambition, and perseverance of effort were entered. This model was statistically significant $F(3,445)$ $=46.91, p<.001$ and explained $24 \%$ of variance in flourishing. In the next step, vitality was entered and the results indicated that the model was statistically significant $F$ $(4,444)=58.06, p<.001$ and explained 34 $\%$ of total variance in flourishing. The introduction of vitality explained an additional $10 \%$ of flourishing when controlling for grit, ambition, and perseverance of effort where $\mathrm{R}^{2}$ change $=$ 0.10 . In the final adjusted model two out of four predictor variables were statistically 

vitality.

significant, with vitality recording a higher Beta value $(\beta=.38, \mathrm{p}<.001)$ than ambition $(\beta=.24, \mathrm{p}<.001)$.

\section{DISCUSSION}

The study was designed to determine the impact of grit and vitality on flourishing. Statistical analyses revealed a significant positive correlation between grit and consistency of interest, ambition, perseverance of effort, vitality and flourishing; between consistency of interest and perseverance of effort; between ambition and perseverance of effort, vitality and flourishing; between perseverance of effort and vitality and flourishing; and between vitality and flourishing. All the significant predictors (grit, ambition, perseverance of effort, vitality) of flourishing were entered into a hierarchical regression model.

Keyes (2005) ${ }^{[27]}$ operationalized flourishing as elevated emotional, psychological, and social well-being. Though there is literature supporting the relationship between grit and well-being (Reed \& Jeremiah, 2017) ${ }^{[28]}$ and well-being and flourishing (Keyes, 2002; Diener et al., 2010) $[13,24]$ that suggest a plausible relationship between grit and flourishing, not many studies attempted to empirically establish the same. The findings of this study are supported by previous literature. A study on a sample of 240 participants (NCC Cadets and Non-NCC Cadets) revealed a relationship between grit and flourishing (Jain \& Sunkarapalli, 2019) ${ }^{[29]}$ and in another study conducted on 101 Indian postgraduate students, grit along with resilience and meaningfulness emerged as a strong predictor of flourishing (Aswini \& Deb, 2017). ${ }^{[30]}$

Also, variables closely associated with grit have predicted flourishing. Ambition is an adaptive personality trait and can foster the state of flourishing in individuals. It is also seen to have a potential influence on the cognitive and everyday functioning of patients living with HIV (Moore et al.,2018). ${ }^{[31]}$ Previous literature has supported the relationship between perseverance of effort and flourishing. A study conducted on 606 Filipino students revealed that perseverance of effort positively predicted flourishing (Datu et al., 2016). ${ }^{[7]}$ In two separate studies on Japanese undergraduate students and Filipino employees, Datu et al. (2021) ${ }^{\text {[32] }}$ examined the link between grit and wellbeing outcomes. Their findings showed that perseverance of effort correlated with flourishing.

Vitality, being an aspect of wellbeing, is a strong indicator of an individual's complete functioning (Ryan \& Deci, 2001). ${ }^{[11]}$ Vitality has been associated with well-being in previous research. Toner et al. (2012) ${ }^{[33]}$ observed a relationship between vitality and well-being in adolescents $(\mathrm{N}=501)$. Another study revealed the mediating role of subjective vitality between diet quality and subjective well-being in college students (Jackson \& DiPlacido, 2019). ${ }^{[34]}$ This may explain the relationship between subjective vitality and flourishing, as flourishing is a descriptor of well-being and is also used as a measure of well-being (Diener, et al., 2010). ${ }^{[24]}$

Based on the objective of this study, positive associations between grit and vitality; grit and flourishing and vitality and flourishing were established. The associations between these variables can be understood based on the role of character strengths in an individual's flourishing experience. A high level of grit ensures people to pursue their goals and never give up on the same, ultimately resulting in positive outcomes. Further, feeling energetic, vital and activated may help such individuals to sustain/persevere towards their goals. Both grit and vitality are variables that operate intrinsically, hence, individuals high on grit and vitality have better flourishing outcomes.

\section{CONCLUSION AND IMPLICATIONS}

Vitality, grit and flourishing are important variables in the context of positive psychology. Grit and vitality, 

vitality.

largely understood as components of character strengths need to be explored in order to see their impact on flourishing. Not much research has been conducted on these variables, especially in the Indian context. The results of this study establish the role of grit and vitality in predicting flourishing, which indicates the need to investigate these links further. It is important to foster flourishing across domains and life stages to ensure optimal functioning. In this regard, it is important to understand the variables associated with flourishing. Further, the results of this study will also contribute towards the development of positive psychological interventions (PPIs) beyond clinical settings.

\section{ACKNOWLEDGEMENTS}

We would like to acknowledge the contribution of the students of University of Hyderabad during data collection. We would also like to thank the participants for participating in the study.

Conflict of Interest: There is no conflict of interest

\section{Source of Funding: None}

\section{Ethical Approval: Approved}

\section{REFERENCES}

1. Baumgardner S, Crothers M. Positive psychology. Pearson Education India; 2015.

2. Duckworth AL, Peterson C, Matthews MD, Kelly DR. Grit: perseverance and passion for long-term goals. Journal of personality and social psychology. 2007 Jun;92(6): 1087.

3. Stoffel JM, Cain J. Review of grit and resilience literature within health professions education. American Journal of Pharmaceutical Education. 2018 Mar $1 ; 82(2)$.

4. American Psychological Association. APA Dictionary of Psychology [Internet]. Washington DC; 2020 [cited 2020 May 10]. Available from: https://dictionary.apa.org/grit.
5. Masten AS. Global perspectives on resilience in children and youth. Child development. 2014 Jan;85(1):6-20.

6. Datu JA, Valdez JP, King RB. Perseverance counts but consistency does not! Validating the short grit scale in a collectivist setting. Current Psychology. 2016 Mar 1;35(1):12130.

7. Datu JA, Valdez JP, King RB. The successful life of gritty students: Grit leads to optimal educational and well-being outcomes in a collectivist context. In The psychology of Asian learners 2016 (pp. 503516). Springer, Singapore.

8. NKP, Shobanah, KR. A study on grit among MBA, MBBS and engineering students. International Journal of Education and Psychological Research. 2017; 6(2):37-43.

9. Maltby J, Day L, Giles D, Gillett R, Quick M, Langcaster-James H, Linley PA. Implicit theories of a desire for fame. British Journal of Psychology. 2008 May;99(2):279-92.

10. Ryan RM, Frederick C. On energy, personality, and health: Subjective vitality as a dynamic reflection of well-being. Journal of personality. 1997 Sep;65(3):52965.

11. Ryan RM, Deci EL. To be happy or to be self-fulfilled: A review of research on hedonic and eudaimonic well-being. Annual review of psychology. 2001;52(16):141-66.

12. Lopez SJ, Pedrotti JT, Snyder CR. Positive psychology: The scientific and practical explorations of human strengths. Sage Publications; 2018 Aug 6.

13. Keyes CL. The mental health continuum: From languishing to flourishing in life. Journal of health and social behavior. 2002 Jun 1:207-22.

14. Fredrickson BL, Losada MF. Positive affect and the complex dynamics of human flourishing. American psychologist. 2005 Oct;60(7):678.

15. Hodge $\mathrm{B}$, Wright $\mathrm{B}$, Bennett $\mathrm{P}$. The role of grit in determining engagement and academic outcomes for university students. Research in Higher Education. 2018 Jun; 59(4):448-60.

16. Singh K, Jha SD. Positive and negative affect, and grit as predictors of happiness and life satisfaction. Journal of the Indian Academy of Applied Psychology. 2008 Apr;34(2):40-5.

17. Bowman NA, Hill PL, Denson N, Bronkema R. Keep on truckin'or stay the 
course? Exploring grit dimensions as differential predictors of educational achievement, satisfaction, and intentions. Social Psychological and Personality Science. 2015 Aug;6(6):639-45.

18. Goodman FR, Disabato DJ, Kashdan TB, Machell KA. Personality strengths as resilience: A one-year multiwave study. Journal of personality. 2017 Jun;85(3):42334.

19. Muenks K, Wigfield A, Yang JS, O'Neal CR. How true is grit? Assessing its relations to high school and college students' personality characteristics, self-regulation, engagement, and achievement. Journal of Educational Psychology. 2017 Jul;109(5):599.

20. Muenks K, Yang JS, Wigfield A. Associations between grit, motivation, and achievement in high school students. Motivation Science. 2018 Jun;4(2):158.

21. Weisskirch RS. Grit, self-esteem, learning strategies and attitudes and estimated and achieved course grades among college students. Current Psychology. 2018 Mar;37(1):21-7.

22. Kannangara CS, Allen RE, Waugh G, Nahar N, Khan SZ, Rogerson S, Carson J. All that glitters is not grit: Three studies of grit in university students. Frontiers in psychology. 2018 Aug 29; 9:1539.

23. McMahan EA, Estes D. Measuring lay conceptions of well-being: The beliefs about well-being scale. Journal of Happiness Studies. 2011 Apr;12(2):267-87.

24. Diener E, Wirtz D, Tov W, Kim-Prieto C, Choi DW, Oishi S, Biswas-Diener R. New well-being measures: Short scales to assess flourishing and positive and negative feelings. Social indicators research. 2010 Jun 1;97(2):143-56.

25. Bostic TJ, Rubio DM, Hood M. A validation of the subjective vitality scale using structural equation modeling. Social Indicators Research. 2000 Dec;52(3):31324.

26. Fini AA, Kavousian J, Beigy A, Emami M. Subjective vitality and its anticipating variables on students. Procedia-Social and Behavioral Sciences. 2010 Jan 1;5:150-6.

27. Keyes CL. Mental illness and/or mental health? Investigating axioms of the complete state model of health. Journal of consulting and clinical psychology. 2005 Jun;73(3):539.

28. Reed L, Jeremiah J. Student grit as an important ingredient for academic and personal success. InDevelopments in Business Simulation and Experiential Learning: Proceedings of the Annual ABSEL conference 2017 (Vol. 44).

29. Jain S, \& Sunkarapalli G. (2019). Relationship between Grit and Flourishing among NCC and NON-NCC Students. International Journal of Indian Psychology. 2019 7(2), 560-570.

30. Aswini S, Deb A. Flourishing among postgraduate students: the role of resilience, meaningfulness and grit. Indian Journal of Community Psychology. 2017 Mar 1;13(1):24.

31. Moore RC, Hussain MA, Watson CW, Fazeli PL, Marquine MJ, Yarns BC, Jeste DV, Moore DJ. Grit and ambition are associated with better neurocognitive and everyday functioning among adults living with HIV. AIDS and Behavior. 2018 Oct;22(10):3214-25.

32. Datu JA, McInerney DM, ŻemojtelPiotrowska M, Hitokoto H, Datu ND. Is grittiness next to happiness? Examining the association of triarchic model of grit dimensions with well-being outcomes. Journal of Happiness Studies. 2021 Feb;22(2):981-1009.

33. Toner E, Haslam N, Robinson J, Williams P. Character strengths and wellbeing in adolescence: Structure and correlates of the Values in Action Inventory of Strengths for Children. Personality and Individual Differences. 2012 Apr 1;52(5):637-42.

34. Jackson CE, DiPlacido J. Vitality as a mediator between diet quality and subjective wellbeing among college students. Journal of Happiness Studies. 2019 Jul 5:1-23.

How to cite this article: Padhy M, Hariharan M, Mutnury SL et.al. Flourishing: role of perseverance and passion for long-term goals in relation to subjective vitality. Int $J$ Health $\mathrm{Sci}$ Res. 2021; 11(6): 6-12. DOI: https://doi.org/10. 52403/ijhsr.20210602 